\title{
(6) OPEN ACCESS \\ Titanium dioxide nanoparticles exacerbate DSS-induced colitis: role of the NLRP3 inflammasome
}

\author{
Pedro A Ruiz, ${ }^{1}$ Belen Morón, ${ }^{1}$ Helen M Becker, ${ }^{1}$ Silvia Lang, ${ }^{1}$ Kirstin Atrott, ${ }^{1}$ \\ Marianne R Spalinger, ${ }^{1}$ Michael Scharl, ${ }^{1,2}$ Kacper A Wojtal, ${ }^{1}$ \\ Anne Fischbeck-Terhalle, ${ }^{1}$ Isabelle Frey-Wagner, ${ }^{1}$ Martin Hausmann, ${ }^{1}$ \\ Thomas Kraemer, ${ }^{3}$ Gerhard Rogler ${ }^{1,2}$
}

- Additional material is published online only. To view please visit the journal online (http://dx.doi.org/10.1136/ gutjnl-2015-310297).

${ }^{1}$ Division of Gastroenterology and Hepatology, University of Zurich, Zurich, Switzerland ${ }^{2}$ Zurich Center for Integrative Human Physiology, University of Zurich, Zurich, Switzerland ${ }^{3}$ Department of Forensic Pharmacology and Toxicology, Institute of Forensic Medicine, University of Zurich, Zurich, Switzerland

Correspondence to Professor Dr Gerhard Rogler, Division of Gastroenterology and Hepatology, University of Zurich, Raemistrasse 100, Zurich 8091, Switzerland; gerhard.rogler@usz.ch

PAR, BM and HMB have contributed equally

Received 6 July 2015 Revised 19 January 2016 Accepted 20 January 2016 Published Online First 16 March 2016

\section{ABSTRACT}

Objective Western lifestyle and diet are major environmental factors playing a role in the development of IBD. Titanium dioxide $\left(\mathrm{TiO}_{2}\right)$ nanoparticles are widely used as food additives or in pharmaceutical formulations and are consumed by millions of people on a daily basis. We investigated the effects of $\mathrm{TiO}_{2}$ in the development of colitis and the role of the nucleotide-binding oligomerisation domain receptor, pyrin domain containing (NLRP)3 inflammasome.

Design Wild-type and NLRP3-deficient mice with dextran sodium sulfate-induced colitis were orally administered with $\mathrm{TiO}_{2}$ nanoparticles. The proinflammatory effects of $\mathrm{TiO}_{2}$ particles in cultured human intestinal epithelial cells (IECS) and macrophages were also studied, as well as the ability of $\mathrm{TiO}_{2}$ crystals to traverse IEC monolayers and accumulate in the blood of patients with IBD using inductively coupled plasma mass spectrometry.

Results Oral administration of $\mathrm{TiO}_{2}$ nanoparticles worsened acute colitis through a mechanism involving the NLRP3 inflammasome. Importantly, crystals were found to accumulate in spleen of $\mathrm{TiO}_{2}$-administered mice. In vitro, $\mathrm{TiO}_{2}$ particles were taken up by IECs and macrophages and triggered NLRP3-ASC-caspase-1 assembly, caspase-1 cleavage and the release of NLRP3associated interleukin (IL)-1 $\beta$ and IL-18. $\mathrm{TiO}_{2}$ also induced reactive oxygen species generation and increased epithelial permeability in IEC monolayers. Increased levels of titanium were found in blood of patients with UC having active disease.

Conclusion These findings indicate that individuals with a defective intestinal barrier function and preexisting inflammatory condition, such as IBD, might be negatively impacted by the use of $\mathrm{TiO}_{2}$ nanoparticles.

\section{INTRODUCTION}

The aetiology of IBD remains only partially understood; however, it is now accepted that both Crohn's disease (CD) and UC are caused by interplay of genetic and environmental factors that trigger an inappropriate immune response. ${ }^{12}$ The incidence of IBD is increasing in many nations undergoing 'westernisation', supporting an important role of environmental factors during IBD pathogenesis. $^{3}{ }^{4}$ Among those environmental

\section{Significance of this study}

What is already known on this subject?

- Titanium dioxide induces reactive oxygen species (ROS) formation as well as inflammation in vitro and in vivo.

- The nucleotide-binding oligomerisation domain receptor, pyrin domain containing (NLRP)3 inflammasome is activated in the presence of titanium dioxide.

- Polymorphisms in the NIrp3 gene have been linked to the development of Crohn's Disease.

What are the new findings?

- Oral administration of titanium dioxide nanoparticles worsens intestinal inflammation in the dextran sodium sulfate (DSS) mouse model of colitis.

- Titanium dioxide crystals accumulate in the spleen of DSS-treated mice following oral gavage.

- Titanium dioxide particles accumulate and activate the NLRP3 inflammasome in human intestinal epithelial cells and macrophages.

- Levels of titanium are increased in the blood of patients with IBD.

How might it impact on clinical practice in the foreseeable future?

- Components of the inflammasome may represent novel therapeutic targets for the treatment of IBD.

- Our results suggest a cautionary use of titanium dioxide in pharmaceutical formulations and support a therapeutic benefit from low inorganic particle diet in patients with IBD.

triggers are the increased hygiene and 'Western diet', which includes ingestion of nanoparticles. ${ }^{5}{ }^{6}$

Inorganic nanoparticles and microparticles are used as additives to influence the appearance of a dietary product. The most commonly used additives are submicron-sized (100-1000 nm diameter) particles of titanium dioxide $\left(\mathrm{TiO}_{2}, \mathrm{E} 171\right)$ and aluminium silicate (E559). Food and pharma grade 
$\mathrm{TiO}_{2}$ is found both in its bulk form and as nanoparticle. In fact, at least $36 \%$ of the $\mathrm{TiO}_{2}$ particles present in food consists of nanoparticles with a particle diameter less than $100 \mathrm{~nm}^{7}$ The daily intake of $\mathrm{TiO}_{2}$ was estimated by the European Food Safety Authorities in 2004 to be $1.28 \mathrm{mg} / \mathrm{kg}$ bodyweight. ${ }^{8}$ Further to this, in a dietary study assessing the $\mathrm{TiO}_{2}$ consumption of patients with $\mathrm{CD}$ and healthy volunteers Lomer $e$ t $a l^{9}$ estimated that the median individual $\mathrm{TiO}_{2}$ intake in both groups was $2.5 \mathrm{mg} /$ day. A later study estimated a daily intake of $\mathrm{TiO}_{2}$ food grade of $0.2-2 \mathrm{mg} / \mathrm{kg}$ bodyweight, ${ }^{7}$ evidencing that $\mathrm{TiO}_{2}$ is ingested in substantial amounts on a daily basis. To date, no restrictions for the use of $\mathrm{TiO}_{2}$ are enforced by food safety authorities and only good manufacturing practice guidelines limit the use of these compounds. ${ }^{10}{ }^{11} \mathrm{An}$ increasing body of literature has revealed that exposure to $\mathrm{TiO}_{2}$ can cause adverse effects, including the production of reactive oxygen species (ROS), ${ }^{12}$ inflammatory responses and tumour formation. ${ }^{13}$ In mice, $\mathrm{TiO}_{2}$ nanoparticles cause genotoxic effects in blood cells, bone marrow and liver, and DNA deletions in the offspring. ${ }^{14}$ Cytotoxic effects resulting from $\mathrm{TiO}_{2}$-induced production of ROS were observed in human lymphoblastoid cells, ${ }^{15}$ fibroblasts, bronchial epithelial cells ${ }^{16}$ and alveolar macrophages, ${ }^{17}$ which led to the classification of $\mathrm{TiO}_{2}$ as 'possibly carcinogenic for humans'. Nanoparticles can accumulate in several organs, such as kidney, lung, brain, liver and spleen. ${ }^{18}{ }^{19}$ In intestinal biopsies, dark aggregates of $\mathrm{TiO}_{2}$ were detected in M-cells of Peyer's patches and in underlying macrophages. ${ }^{20}$ Interestingly, these sites of $\mathrm{TiO}_{2}$ uptake correspond to regions where first signs of inflammation in patients with CD manifest. ${ }^{21}$

Nucleotide-binding oligomerisation domain receptor, pyrin domain containing (NLRP) 3 is a member of the Nod-like receptor (NLR) family that regulates the activation of caspase- 1 by forming signalling complexes called 'inflammasomes'. On activation, NLRP3 binds to the apoptosis-associated speck-like protein containing a caspase recruitment domain (ASC) adapter protein, which in turn recruits and activates caspase-1. Activated caspase-1 cleaves pro-interleukin (IL)- $1 \beta$ and pro-IL-18 into their biologically active forms. ${ }^{22}{ }^{23}$ Single nucleotide polymorphisms in the Nlrp3 gene have been linked to the development of CD. ${ }^{24}$ NLRP3 has been shown to be activated by a wide range of pathogens and intrinsic danger signals like ATP, ${ }^{25}$ ROS, crystalline monosodium urate, ${ }^{26}$ cholesterol crystals ${ }^{27}$ and inorganic materials like aluminium salts, ${ }^{28}$ asbestos and silica crystals. ${ }^{29}$ Similarly, inorganic $\mathrm{TiO}_{2}$ nanoparticles activate the NLRP3 inflammasome and induce a proinflammatory response in human keratinocytes, human dendritic cells and murine macrophages. ${ }^{23}$

In the present study, we analysed the effect of $\mathrm{TiO}_{2}$ on intestinal inflammation as well as the contribution of the NLRP3 inflammasome in $\mathrm{TiO}_{2}$-mediated inflammatory responses. For this purpose, we used the dextran sodium sulfate (DSS) acute colitis model in the wild-type (WT) and NLRP3-deficient $\left(\mathrm{Nlrp}^{-/-}\right)$mice. Oral administration of $\mathrm{TiO}_{2}$ nanoparticles worsened intestinal inflammation through NLRP3. Moreover, crystals were found to accumulate in splenic tissue of $\mathrm{TiO}_{2}$-administered mice, but not in those receiving water. In vitro experiments showed that both $\mathrm{TiO}_{2}$ nanoparticles and food grade $\mathrm{TiO}_{2}$ microparticles trigger proinflammatory cytokine secretion through NLRP3 inflammasome activation, and accumulate in human intestinal epithelial cells (IECs) and macrophages. $\mathrm{TiO}_{2}$ particles induced ROS production in IECs and increased epithelial permeability. Finally, an increase of titanium burden in blood of patients with UC having active disease was found, evidencing an impaired barrier function and suggesting that $\mathrm{TiO}_{2}$ nanoparticles could pose a specific risk to patients with IBD.

\section{MATERIAL AND METHODS \\ Mouse experiments}

Acute colitis was induced in female WT (C57BL/6J) and $\mathrm{Nlrp} 3^{-1-}$ mice between 12 and 14 weeks of age by oral administration of $1.5 \% \mathrm{DSS}^{30}$ (MP Biomedicals) in drinking water ad libitum for 7 days. A suspension of $\mathrm{TiO}_{2}$ nanoparticles (rutile, $30-50 \mathrm{~nm}$, IoLiTec) in drinking water was administered daily by oral gavage. WT mice were divided in three groups of 12 mice each, and received water, 50 or $500 \mathrm{mg} \mathrm{TiO}_{2} /$ day $/ \mathrm{kg}$ bodyweight. Nlrp $3^{-/-}$mice received water $(\mathrm{n}=10)$ or $500 \mathrm{mg} \mathrm{TiO} /$ day $/ \mathrm{kg}$ bodyweight $(\mathrm{n}=10)$. On day 8 , colitis was assessed by endoscopy and mice were sacrificed for sample collection. All the animal experiments were approved by the veterinary authorities of Zurich, Switzerland.

\section{Colonoscopy and determination of histological score}

Animals were anaesthetised intraperitoneally with a mixture of ketamine $90-120 \mathrm{mg} / \mathrm{kg}$ bodyweight (Vétoquinol) and xylazine $8 \mathrm{mg} / \mathrm{kg}$ bodyweight (Bayer), and colonoscopy was performed as described previously. ${ }^{31}$ Animals were sacrificed and colon length was measured. About $1 \mathrm{~cm}$ of tissue was removed from the distal third of the colon and fixed in 4\% formalin overnight. H\&E stained sections of the paraffin-embedded tissue were used for histological analysis. Histological score was determined as described previously ${ }^{32} 33$ by two independent, blinded investigators.

\section{Western blotting and co-immunoprecipitation}

Total protein from cell monolayers was harvested into M-PER lysis buffer (Thermo Fisher Scientific) and western blotting was performed to determine the expression of NLRP3 (Enzo life sciences), caspase-1, ASC, IL-1 $\beta$ (Cell Signaling Technologies) and IL-18 (MBL). Co-immunoprecipitation (Co-IP) was performed overnight at $4^{\circ} \mathrm{C}$ using NLRP3 antibody. Immunocomplexes were collected with Protein G Sepharose beads (GE Healthcare) for $1 \mathrm{~h}$ at $4^{\circ} \mathrm{C}$ prior to western blotting.

\section{Microscopy of spleen cryosections and Caco-2 monolayers}

Confocal reflection microscopy was combined with fluorescence microscopy in a Leica SP8 laser scanning confocal microscope, as described previously. ${ }^{28}$ Caco-2 cells grown on coverslips and transwells were fixed with 4\% PFA for $20 \mathrm{~min}$. Coverslips were directly subjected to $H \& E$ staining. Cryosections of transwells with Caco-2 monolayers were cut at cryogenic temperatures at 5-20 $\mu \mathrm{m}$ thickness. Sections were stained with H\&E or DAPI-containing mounting medium (Vector Laboratories) and images were captured using a fluorescent microscope (Axioplan2, Zeiss). For electron microscopy, Caco-2 cells were fixed and embedded in Epon according to established protocols. ${ }^{34}$ Electron microscopic analysis, including elemental analysis was performed with a CM12 electron microscope (FEI) equipped with an EDX detector (Genesis, EDAX). For quantification of intracellular microparticles, $5 \mu \mathrm{m}$ sections of $\mathrm{TiO}_{2}$-stimulated Caco-2 monolayers grown on transwell membranes were used. Particles and aggregates of $\mathrm{TiO}_{2}$ were counted in phase-contrast view, and DAPI-stained nuclei were counted in blue fluorescent channel.

\section{Cell culture and reagents}

THP-1 cells were maintained in RPMI medium (Invitrogen) supplemented with $10 \%$ fetal calf serum (VWR). To induce differentiation, $40 \mathrm{nM}$ phorbol-12-myristate-13-acetate (Sigma- 
Aldrich) was added to $0.5 \times 10^{6}$ cells $/ \mathrm{mL}$. Caco- 2 and HT-29 were obtained from the German Collection of Cells and Microorganisms (DSMZ). Other IEC lines were provided and previously described ${ }^{35}$ by the Department of Internal Medicine Regensburg and cultured under conditions as recommended by the DSMZ. Inflammasome activation was triggered in IECs with crude lipopolysaccharide (Santa Cruz) at a concentration of $10 \mu \mathrm{g} / \mathrm{mL}$. $\mathrm{TiO}_{2}$ (AHRSE; geometric particle size of ca $0.36 \mu \mathrm{m}$, PSD of around 1.35), an uncoated anatase of high purity used in cosmetics and food, was obtained from Huntsman Pigments. Particles were sterilised by addition of $1 \mathrm{~mL} 70 \%$ ethanol to $20 \mathrm{mg} \mathrm{TiO}_{2}$ and by subsequently vacuum freeze-drying. Particles were resuspended in ultrapure water and sonicated for 5 min to obtain a homogenous suspension.

\section{Isolation and stimulation of bone marrow-derived macrophages}

Mononuclear phagocyte progenitor cells were flushed from femural and tibial bones from C57/BL6 mice with cell culture medium. After centrifugation, cells were resuspended in medium containing $30 \mathrm{ng} / \mathrm{mL}$ recombinant murine macrophagestimulating factor (Biovision) and kept for 5 days before stimulation with $20 \mu \mathrm{g} / \mathrm{mL} \mathrm{TiO}_{2}$ and $5 \mu \mathrm{M}$ cytochalasin D (Invivogen).

\section{ELISA analysis}

ELISAs directed against active forms of IL-1 $\beta$ (R\&D Systems) and IL-18 (MBL) were conducted with cell culture supernatants according to manufacturer's instructions.

\section{Small interfering RNA knockdown of inflammasome components}

Undifferentiated THP-1 cells were transfected with three sets of small interfering RNAs (siRNAs) for caspase-1, ASC and NLRP3 at a concentration of 100 pmol each, and electroporated using the Amaxa nucleofector kit (Mirus Bio LLC) following manufacturer's instructions.

\section{Assessment of lysosomal integrity}

Caco- 2 and HT-29 cells were stained with $1 \mu \mathrm{g} / \mathrm{mL}$ acridine orange (Sigma-Aldrich) for 15 min prior to $\mathrm{TiO}_{2}$ and cytochala$\sin \mathrm{D}$ stimulation. Lysosomal rupture was analysed by fluorescent microscopy (Axioplan2, Zeiss).

\section{Measurement of ROS production}

IECs were incubated with Hank's balanced salt solution (HBSS) (Sigma-Aldrich) containing $50 \mu \mathrm{M}$ of dihydro-dichlorofluorescin diacetate (Sigma-Aldrich) for $30 \mathrm{~min}$ at $37^{\circ} \mathrm{C}$. ROS-induced fluorescence was detected using a microplate reader with an excitation wavelength of $485 \mathrm{~nm}$ and an emission wavelength of $528 \mathrm{~nm}$.

\section{Epithelial permeability studies}

Caco- 2 cells were grown as monolayers on transwell membranes as described above. Flux of fluorescein isothiocyanate-dextran beads (average molecular weight 40000 , Sigma-Aldrich) was measured $2 \mathrm{~h}$ after addition of $1 \mathrm{mg} / \mathrm{mL}$ beads to the apical compartment. Fluorescence intensity in aliquots from the basolateral compartment was measured using a microplate reader with an excitation wavelength of $485 \mathrm{~nm}$ and an emission wavelength of $525 \mathrm{~nm}$.

\section{Human subjects}

The study was conducted as a subproject of the Swiss IBD Cohort Study and was approved by the Ethics Committees (EK
1316). ${ }^{36}$ Prior to inclusion into the study, written informed consent was obtained from all patients. Inclusion criteria for enrolment of patients with IBD having active disease were $18-80$ years of age and at least one episode of active disease between 1 September 2010 and 31 August 2011. Flare-up episodes reported by the patient were verified by a physician in the course of a clinical examination. Inclusion criteria for enrolment of patients with IBD in clinical remission were $18-80$ years of age and maintenance of clinical remission between 1 September 2010 and 31 August 2011. Exclusion criteria in this study were perianal CD and positive results of microbiological workup of faecal samples for known infectious agents. Clinical activity in patients with CD and patients with UC was assessed using the Harvey Bradshaw Index (HBI) ${ }^{37}$ and the Rachmilewitz Index, ${ }^{38}$ respectively. A flare-up episode in patients with CD was defined as a rise in HBI value of $\geq 4$ points. A flare-up in patients with UC was defined as an increase in the Rachmilewitz Index value of $\geq 5$ points. Titanium levels in blood samples from healthy volunteers $(n=28)$, patients with UC having active disease $(n=5)$, patients with UC in remission $(n=6)$, patients with CD having active disease $(n=8)$ and patients with $C D$ in remission $(n=9)$ were measured by inductively coupled plasma mass spectrometry (ICP-MS) at the Department of Forensic Pharmacology and Toxicology of the University of Zurich, Switzerland.

\section{Inductively coupled plasma mass spectrometry}

\section{Sample preparation for ICP-MS}

All calibration standard solutions were prepared from $1 \mathrm{mg} / \mathrm{mL}$ single element standard solutions (Merck) by dilution with ultrapure water. About $0.5 \mathrm{~mL}$ of whole blood from patients was diluted in $4.5 \mathrm{~mL}$ ultrapure water and infused into the ICP-MS. Seronorm trace elements whole blood samples (level 3; titanium concentration: $24 \mu \mathrm{g} / \mathrm{L}$; accepted range $20-28 \mu \mathrm{g} / \mathrm{L}$ ) were prepared in the same manner as the whole blood samples from patients and used as control (SERO AS).

\section{ICP-MS}

A Varian ICP-MS 810 (low resolution) equipped with type 142 Varian cooler and a Varian SPS 3 Autosampler (Varian) were used with the following measurement parameters: analysis type: quantitative; acquisition mode: steady state; scan mode: peak hopping; spacing: coarse; points/peak: 1; scans/replicate: 50; replicates/sample: 3; plasma flow: $18.00 \mathrm{~L} / \mathrm{min}$; auxiliary flow: $1.75 \mathrm{~L} / \mathrm{min}$; sheath gas flow: $0.24 \mathrm{~L} / \mathrm{min}$; nebuliser flow: $1.00 \mathrm{~L} / \mathrm{min}$; sampling depth: $5.00 \mathrm{~mm}$; power: $1.35 \mathrm{~kW}$; pump rate: $7 \mathrm{rpm}$; stabilisation delay $0 \mathrm{~s}$; ion optics (volt) version number: 0; first extraction lens: -1.00 ; second extraction lens: -129.00 ; third extraction lens: -214.00 ; left mirror lens: 32.00; right mirror lens: 17.00; bottom mirror lens: 28.00; corner lens: -199.00 ; entrance lens: -1.00 ; fringe bias: -4.50 ; entrance plate: -32.00 ; detector focus: true pole bias: 0.00; sampling aerosol generation: nebuliser, source: autosampler; fast pump during sample delay/rinse: On; probe height: $0 \mathrm{~mm}$; premix: Off; rinse time: $10 \mathrm{~s}$; spray chamber cooling: on spray chamber temperature: $3.00^{\circ} \mathrm{C}$; sample uptake delay: $50 \mathrm{~s}$; smart rinse: No; switch delay: OFF; scan time: $1415 \mathrm{~ms}$; replicate time: $70.75 \mathrm{~s}$; titanium isotope for quantification: 49. All chemicals (eg, water, acid, hydrogen peroxide) and materials (eg, tubes, blood Monovettes including needles) were checked for interferences. All results were under the detection limit of the procedure $(0.25 \mu \mathrm{g} / \mathrm{L})$. Calibration was done in every series, using standard solutions of 1,10 and $100 \mu \mathrm{g} / \mathrm{L}$ Titanium and a blank. The results of the Seronorm quality control samples were very good. Mean $(n=14)$ of the results of the Seronorm control 
level 3 (target value $24 \mu \mathrm{g} / \mathrm{L}$ ) was $24.5 \mu \mathrm{g} / \mathrm{L}$ with a coefficient of variation of $9.6 \%$. Thus, the method was more than suitable for our purposes, especially considering that, while accuracy may be marginally compromised, relative differences between the groups should stay the same.

\section{Statistics}

Statistical analysis was performed using Student's t test, MannWhitney test or one-way analysis of variance with Dunnett's post-test. The results are expressed as mean \pm SEM and significance was set as $\mathrm{p}<0.05$.

\section{RESULTS}

\section{Administration of $\mathrm{TiO}_{2}$ nanoparticles aggravates}

\section{DSS-induced colitis}

To study the impact of $\mathrm{TiO}_{2}$ nanoparticles in colitis, and the role of NLRP3 inflammasome in $\mathrm{TiO}_{2}$-mediated effects, DSS-treated WT and $N l r p 3^{-/-}$mice were administered with 0 , 50 or $500 \mathrm{mg} / \mathrm{kg} /$ day $\mathrm{TiO}_{2}$ nanoparticles by oral gavage. WT mice receiving $\mathrm{TiO}_{2}$ presented a more severe colitis than mice receiving $\mathrm{TiO}_{2}$-free drinking water, as evidenced by a significant shortening of the colon (figure 1A), and colonoscopy results (figure 1B). In contrast, Nlrp $3^{-/-}$mice administered with $500 \mathrm{mg} / \mathrm{kg} /$ day $\mathrm{TiO}_{2}$ showed no differences in colon length or colonoscopy findings compared with WT and $N \operatorname{lrp} 3^{-/-}$mice receiving water (figure $1 \mathrm{~A}, \mathrm{~B}$ ). Similarly, $\mathrm{H} \& \mathrm{E}$ stained sections of colonic tissue presented a significantly higher inflammatory cell infiltration (figure 1C) and total histological score with a severe disruption of the mucosal epithelium in $\mathrm{TiO}_{2}$-treated WT, but not $N l r p 3^{-/-}$mice (figure $1 \mathrm{D}, \mathrm{E}$ ). Mice receiving $\mathrm{TiO}_{2}$ in the absence of colitis did not present shortening of the colon, or increased histological scores (data not shown), suggesting that $\mathrm{TiO}_{2}$ might be deleterious only in pre-existing inflammation. Recent studies have shown that, after intravenous injection of $\mathrm{TiO}_{2}$ in rats, significant levels of $\mathrm{TiO}_{2}$ in spleen and liver were still found 30 days post injection. ${ }^{39}$ When applied intraperitoneally in mice, $\mathrm{TiO}_{2}$ was distributed throughout the entire body but was mainly retained in liver and spleen. ${ }^{40}$ In our experimental setting, analysis of splenic cryosections using a combination of confocal and reflexion microscopy revealed that oral administration of $\mathrm{TiO}_{2}$ led to the accumulation of crystals in the spleen of DSS-treated mice in a dose-dependent manner (figure $1 \mathrm{~F}$ ).

\section{$\mathrm{TiO}_{2}$ induces NLRP3 activation and caspase-1 downstream effectors in human IECs and macrophages}

Since IECs have rarely been used in NLRP3 inflammasome studies, protein expression of NLRP3 was confirmed by western blot in human IEC lines (see online supplementary figure S1A). Interestingly, both nanoparticles and microparticles induced IL-1 $\beta$ secretion in the monocytic cell line THP-1 (figure $2 \mathrm{~A}$ ), as well as caspase- 1 cleavage (figure $2 \mathrm{~B}$ ) and IL-1 $\beta$ cleavage (figure 2C) in both Caco-2 and THP-1 cells. Co-IP of NLRP3 further evidenced the association of the inflammasome components caspase-1, ASC and NLRP3 on stimulation with both $\mathrm{TiO}_{2}$
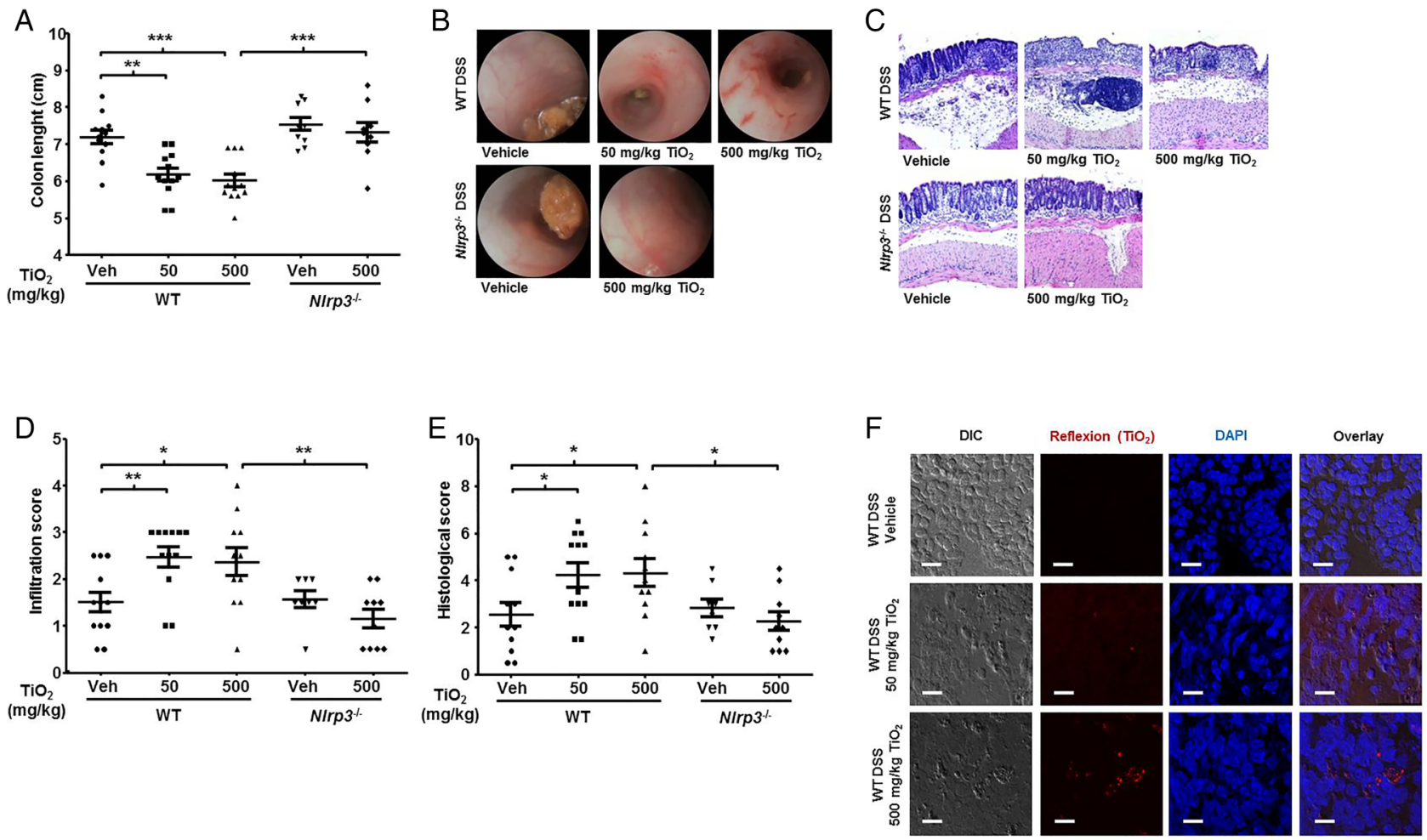

Figure 1 Administration of titanium dioxide $\left(\mathrm{TiO}_{2}\right)$ nanoparticles aggravates colitis in the dextran sodium sulfate (DSS) mouse model of acute colitis through activation of the nucleotide-binding oligomerisation domain receptor, pyrin domain containing (NLRP)3 inflammasome. (A-E) DSS-treated wild-type (WT) and N/rp3 ${ }^{-1-}$ C57BL/6J mice received $\mathrm{TiO}_{2}$ by oral gavage as indicated. Mice were sacrificed at day 8 and colon length was measured (A). Mucosal damage was assessed by colonoscopy (B). H\&E staining of sections displayed severe barrier breakdown (C) with extensive infiltration reaching the lamina muscularis mucosae (D). Total histological score was calculated as the sum of epithelial damage and infiltration score (E). Results represent mean \pm SEM; WT mice: $n=12, N / r p 3^{-l-}$ mice: $n=10,{ }^{*} p<0.05 ;{ }^{* *} p<0.01 ;{ }^{* *} p<0.001$. (F) Cryosections of spleen from DSS-treated WT mice administered with $\mathrm{TiO}_{2}$ or $\mathrm{TiO}_{2}$-free water were fixed and nuclei were stained with DAPI (blue). The presence of crystals (red) was analysed combining confocal reflection microscopy with fluorescence microscopy. Results are representative of four experiments. Scale bars: $10 \mu \mathrm{m}$. 
A

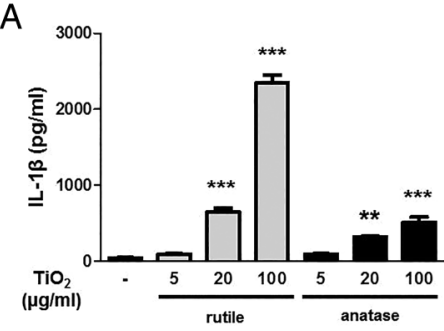

D

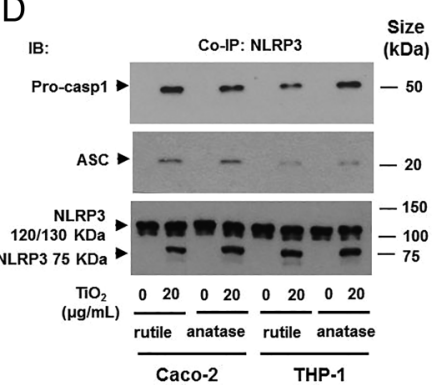

B

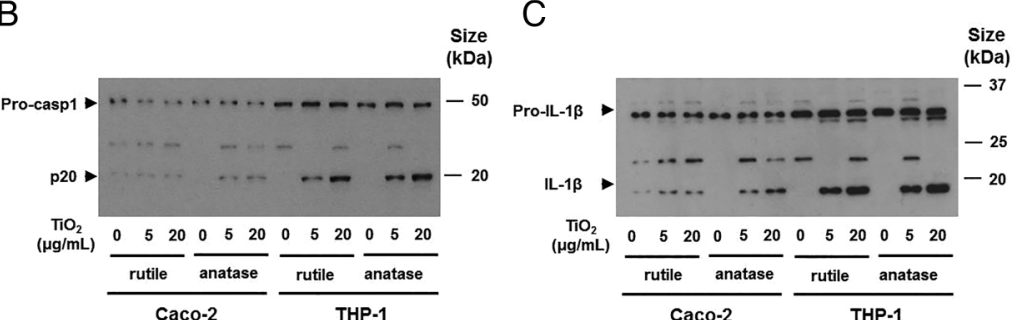

$\mathrm{E}$

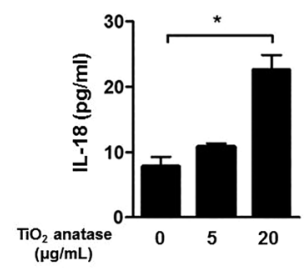

$\mathrm{F}$

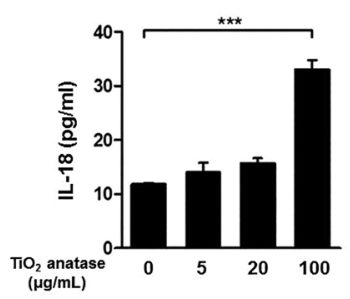

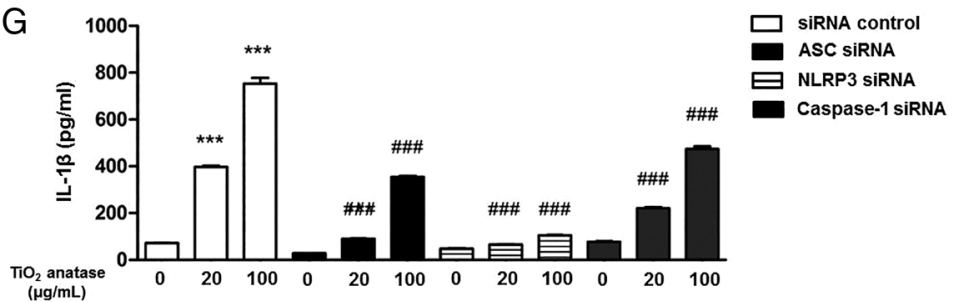

Figure 2 Caspase-1 downstream effectors are activated in macrophages and intestinal epithelial cells (IECs) on exposure to titanium dioxide $\left(\mathrm{TiO}_{2}\right)$. (A) THP-1 cells were treated for $24 \mathrm{~h}$ with indicated amounts of $\mathrm{TiO}_{2}$ nanoparticles and microparticles, and the secretion of active interleukin (IL)- $1 \beta$ in cell culture supernatants was assessed by ELISA ( $\left.n=3,{ }^{* *} p<0.01,{ }^{* * *} p<0.001\right)$. (B-D) Caco-2 and THP-1 cells were treated for $24 \mathrm{~h}$ with indicated amounts of $\mathrm{TiO}_{2}$ nanoparticles and microparticles. The activation of caspase-1 (B) and IL-1 $\beta$ (C) in response to $5 \mu \mathrm{g} / \mathrm{mL} \mathrm{TiO}{ }_{2}$ was detectable in both cell lines. Lysates were subjected to co-immunoprecipitation (Co-IP) using nucleotide-binding oligomerisation domain receptor, pyrin domain containing (NLRP)3-antibody prior to western blotting to detect caspase-1 and ASC (D). (E-G) Incubation of Caco-2 (E) with $\mathrm{TiO}_{2}$ microparticles resulted in release of active IL-18 in cell supernatants $(n=4)$. In THP-1 cells, release of both IL-18 (F) and IL-1 $\beta$ (G) was significantly increased on stimulation with $\mathrm{TiO}_{2}$ microparticles $(n=3, * * * \mathrm{p}<0.001)$, an effect that was dependent on the presence of inflammasome components. Small interfering RNA (siRNA)-mediated knockdown of ASC, NLRP3 or caspase-1 in THP-1 cells resulted in significantly lower levels of IL-1 13 on $\mathrm{TiO}_{2}$ stimulation $(\mathrm{G})\left(\mathrm{n}=3,{ }^{* * *} \mathrm{p}<0.001\right)$.

crystal forms (figure 2D). $\mathrm{TiO}_{2}$ microparticles induced $\mathrm{IL}-18$ cytokine secretion in Caco-2 and THP-1 cells (figure 2E,F). Moreover, siRNA knockdown of the inflammasome components NLRP3, ASC and caspase- 1 in THP-1 cells significantly reduced the levels of IL- $1 \beta$ in the presence of $\mathrm{TiO}_{2}$ demonstrating that $\mathrm{TiO}_{2}$-induced IL-1 $\beta$ release is NLRP3 inflammasomedependent (figure $2 \mathrm{G}$ ).

\section{$\mathrm{TiO}_{2}$ accumulates in human IECs and macrophages in a dose-dependent manner}

In agreement with previous reports, ${ }^{23}$ incubation of THP-1 cells with food grade $\mathrm{TiO}_{2}$ microparticles led to intracellular accumulation of dark aggregates (figure 3A). Additionally, we observed that $\mathrm{TiO}_{2}$ was taken up by murine BMDMs (figure $3 \mathrm{~B}$ ). Pretreatment of BMDMs with cytochalasin D, an inhibitor of endocytosis, did not inhibit the accumulation of $\mathrm{TiO}_{2}$ aggregates (figure $3 \mathrm{C}$ ), pointing to an endocytosis-independent uptake mechanism. As the intestinal epithelium is subjected to the major exposure to $\mathrm{TiO}_{2}$, we investigated whether $\mathrm{TiO}_{2}$ also penetrates IECs. Treatment of monolayers of the IEC lines HT-29 and Caco-2 with $\mathrm{TiO}_{2}$ microparticles for $24 \mathrm{~h}$ resulted in intracellular accumulation of $\mathrm{TiO}_{2}$ (figure 3D,E). To mimic the physiological setting in the intestine, tight monolayers of Caco-2 cells growing on transwell filters were stimulated apically with $\mathrm{TiO}_{2}$. Cross-sections of these monolayers revealed dark, intracellular aggregates of microparticles (figure 4A,B), which were present in a dose-dependent manner (figure 4C,D). These findings were confirmed by electron microscopy: $\mathrm{TiO}_{2}$ was detectable in cross-sections of Caco-2 monolayers as electron dense aggregates (figure 4E) and elemental analysis of selected areas confirmed that aggregates contained titanium (figure 4F).

\section{$\mathrm{TiO}_{2}$ triggers ROS production and epithelial permeability} in IECs

The uptake of $\mathrm{TiO}_{2}$ particles has been associated with the production of ROS, ${ }^{16}$ which are major inducers of NLRP3 inflammasome activation via stress-associated signals. ${ }^{41}$ Our results show that $\mathrm{TiO}_{2}$ microparticles induced ROS production in HT-29 (figure 5A) and Caco-2 cells (figure 5B) in a dosedependent manner. Particulate matter has been shown to induce inflammasome activation through lysosomal rupture following endocytosis. ${ }^{28}$ To investigate whether this is also the case with $\mathrm{TiO}_{2}$ microparticles, lysosomal staining with acridine orange was performed on IECs stimulated with $\mathrm{TiO}_{2}$. Fluorescence microscopy did not show any loss of lysosomal integrity in $\mathrm{TiO}_{2}$-treated Caco-2 and HT-29 cells (see online supplementary figure S2A-C). Based on our results showing intracellular accumulation of $\mathrm{TiO}_{2}$ in epithelial monolayers, we sought to 

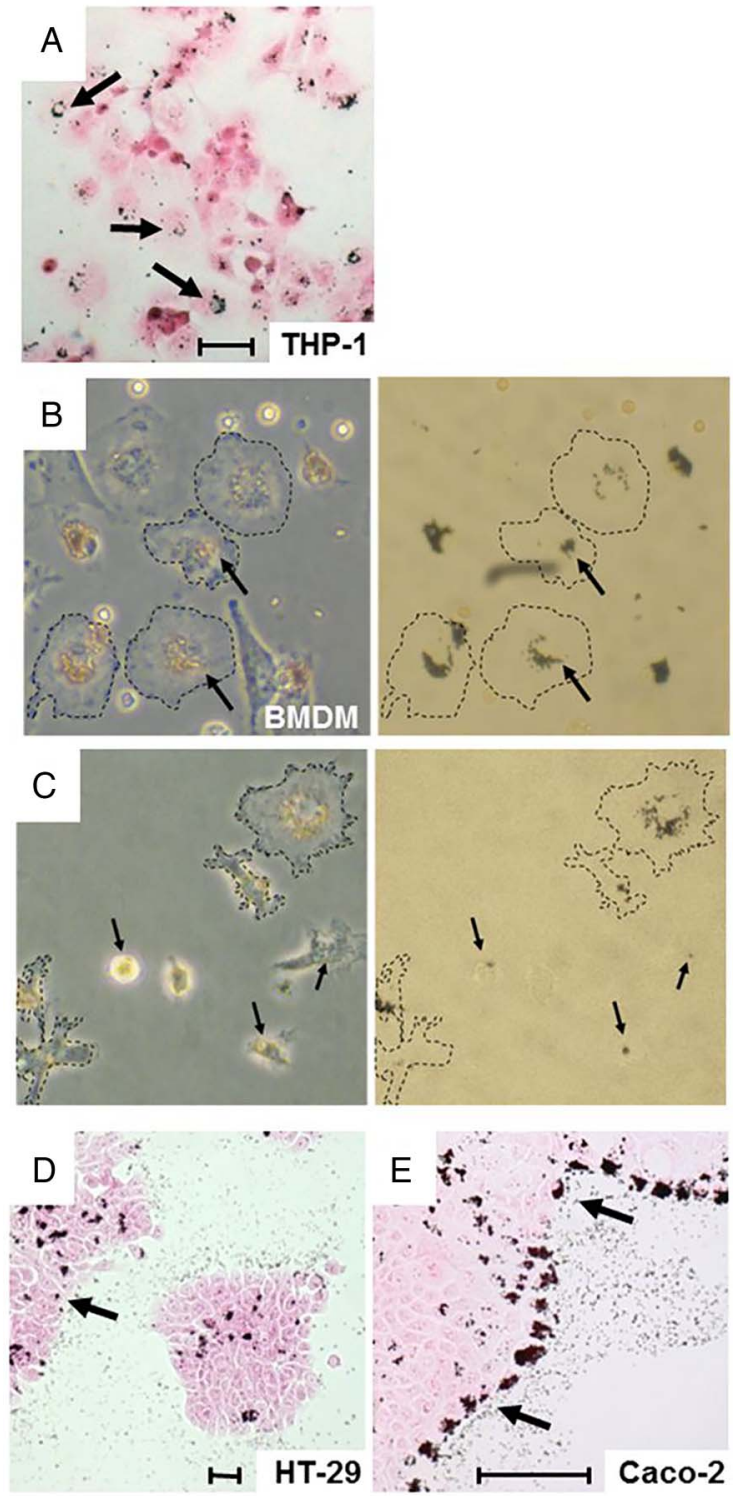

Figure 3 Aggregates of titanium dioxide $\left(\mathrm{TiO}_{2}\right)$ accumulate intracellularly in macrophages and intestinal epithelial cells (IECs). (A) After $24 \mathrm{~h}$ incubation with $100 \mu \mathrm{g} / \mathrm{mL} \mathrm{TiO}_{2}$, THP-1 cells were fixed and stained with eosin. Arrows indicate intracellular $\mathrm{TiO}_{2}$ aggregates. Scale bars: $100 \mu \mathrm{m}$. (B and C) BMDM were stimulated with $20 \mu \mathrm{g} / \mathrm{mL} \mathrm{TiO}$, without (B) or with cytochalasin D (C) for $24 \mathrm{~h}$, and images of live cultures were taken. $\mathrm{TiO}_{2}$ aggregates can be found in all cells, and they show a distinct distribution pattern (arrows). Inhibition of endocytosis with cytochalasin $\mathrm{D}$ did not abolish the uptake of $\mathrm{TiO}_{2}$. (D and $\mathrm{E}$ ) HT-29 (D) and Caco-2 (E) cells were grown on glass cover slips and incubated with $100 \mu \mathrm{g} / \mathrm{mL} \mathrm{TiO}_{2}$ for $24 \mathrm{~h}$. Intracellular aggregates of $\mathrm{TiO}_{2}$ were found in both cell types, indicated by arrows. Scale bar: $100 \mu \mathrm{m}$.

investigate the effects of $\mathrm{TiO}_{2}$ on epithelial permeability. For this purpose, we used the transwell model system with Caco-2 cells, which form tight monolayers with an apical-basolateral polarity. The treatment of Caco- 2 with $20 \mu \mathrm{g} / \mathrm{mL} \mathrm{TiO}_{2}$ resulted in a significant increase of epithelial permeability (figure $5 \mathrm{C}$ ).

\section{Patients with UC having active disease present increased levels of titanium in systemic circulation}

Given the increased permeability in the mucosa of patients with IBD, and based on our findings showing the proinflammatory effects of food-derived $\mathrm{TiO}_{2}$ and its ability to traverse the intestinal mucosa in vivo, we hypothesised that patients with IBD may have a higher systemic burden of titanium. Using ICP-MS, we assessed the levels of titanium in whole blood of healthy donors and patients with IBD. Initial data analysis did not reveal significant differences in titanium levels when comparing healthy donors with patients with IBD (figure 6A). However, we observed significantly higher titanium levels in the subgroup of patients with UC having active disease (figure 6B).

\section{DISCUSSION}

Our results show that oral administration of $\mathrm{TiO}_{2}$ nanoparticles enhances intestinal inflammation in the DSS mouse model of colitis. Although $\mathrm{TiO}_{2}$ concentrations used are higher than the amounts the human gut is daily exposed to, the results obtained suggest that $\mathrm{TiO}_{2}$ is biologically active and support a growing body of literature evidencing the deleterious effects of $\mathrm{TiO}_{2}$ in vivo. ${ }^{12}{ }^{42-44} \mathrm{TiO}_{2}$ proinflammatory effects required NLRP3 inflammasome activation as shown when comparing WT with $N \operatorname{lrp} 3^{-/-}$mice. The role of NLRP3 in DSS colitis is controversial with reports showing detrimental ${ }^{45}{ }^{46}$ and protective ${ }^{47} 48$ roles for NLRP3. In our study, 1.5\% DSS induced a mild inflammation in WT and Nlrp3 $3^{-l-}$ mice and we did not detect significant differences between the two groups. Despite the relatively large consumption of $\mathrm{TiO}_{2}$, stability and aggregation in GI fluids has received limited attention. Recent studies using in vitro human digestion models have shown that $\mathrm{SiO}_{2}$ and $\mathrm{Ag}$ nanoparticles, which agglomerated under conditions of low $\mathrm{pH}$ and high electrolytes as in the gastric compartment, become bioavailable under intestinal conditions. ${ }^{49} 50$ Our mouse experiments demonstrate a dose-dependent accumulation of crystals in the spleen, pointing to the fact that ingested $\mathrm{TiO}_{2}$ can traverse the intestinal mucosa and reach the systemic circulation. This finding agrees with recent studies showing that $\mathrm{TiO}_{2}$ nanoparticles translocate through the intestinal epithelium and accumulate in the spleen in orally administered mice. ${ }^{51} 52$ Of note, we could not find accumulation of $\mathrm{TiO}_{2}$ crystals in the colonic epithelium, suggesting that $\mathrm{TiO}_{2}$ nanoparticles are mostly absorbed in the small intestine. This is in accordance with previous studies showing that $\mathrm{TiO}_{2}$ particles translocate through the epithelium lining the small intestine, in particular Peyer's patches. ${ }^{20} 51$ We show that $\mathrm{TiO}_{2}$ nanoparticles and microparticles induce NLRP3-ASC-caspase-1 assembly and caspase-1 cleavage, resulting in the release of functionally active IL- $1 \beta$ in Caco- 2 and THP- 1 cells in the absence of other stimulus. $\mathrm{TiO}_{2}$ microparticles also induced IL-18 secretion in both cell lines. Since $\mathrm{TiO}_{2}$ microparticles contain a significant amount of nanosized particles, it is likely that the effects observed on microparticle stimulation are due, at least in part, to the presence of $\mathrm{TiO}_{2}$ nanoparticles. Knockdown of NLRP3, ASC and caspase-1 abrogated $\mathrm{TiO}_{2}$-induced IL-1 $\beta$ expression in macrophages, evidencing the crucial role of the NLRP3 inflammasome in $\mathrm{TiO}_{2}$-mediated proinflammatory responses. In vitro experiments showed that $\mathrm{TiO}_{2}$ microparticles are taken up by human nonphagocytic IECs as well as macrophage-like THP-1 cells. In agreement with previous reports showing that $\mathrm{TiO}_{2}$ particles can enter cells via non-endocytic mechanisms, ${ }^{53}$ our results point to that $\mathrm{TiO}_{2}$ uptake was not endocytosis-mediated, and no specific subcellular structure was found to be associated with $\mathrm{TiO}_{2}$ accumulations. Moreover, we did not observe an involvement of lysosomal structures or $\mathrm{TiO}_{2}$-induced lysosomal damage, suggesting that $\mathrm{TiO}_{2}$ particles might interact with lipid membranes and are passively transported into cells, as seen with silica nanoparticles. ${ }^{54} \mathrm{TiO}_{2}$ particles were shown to disturb 

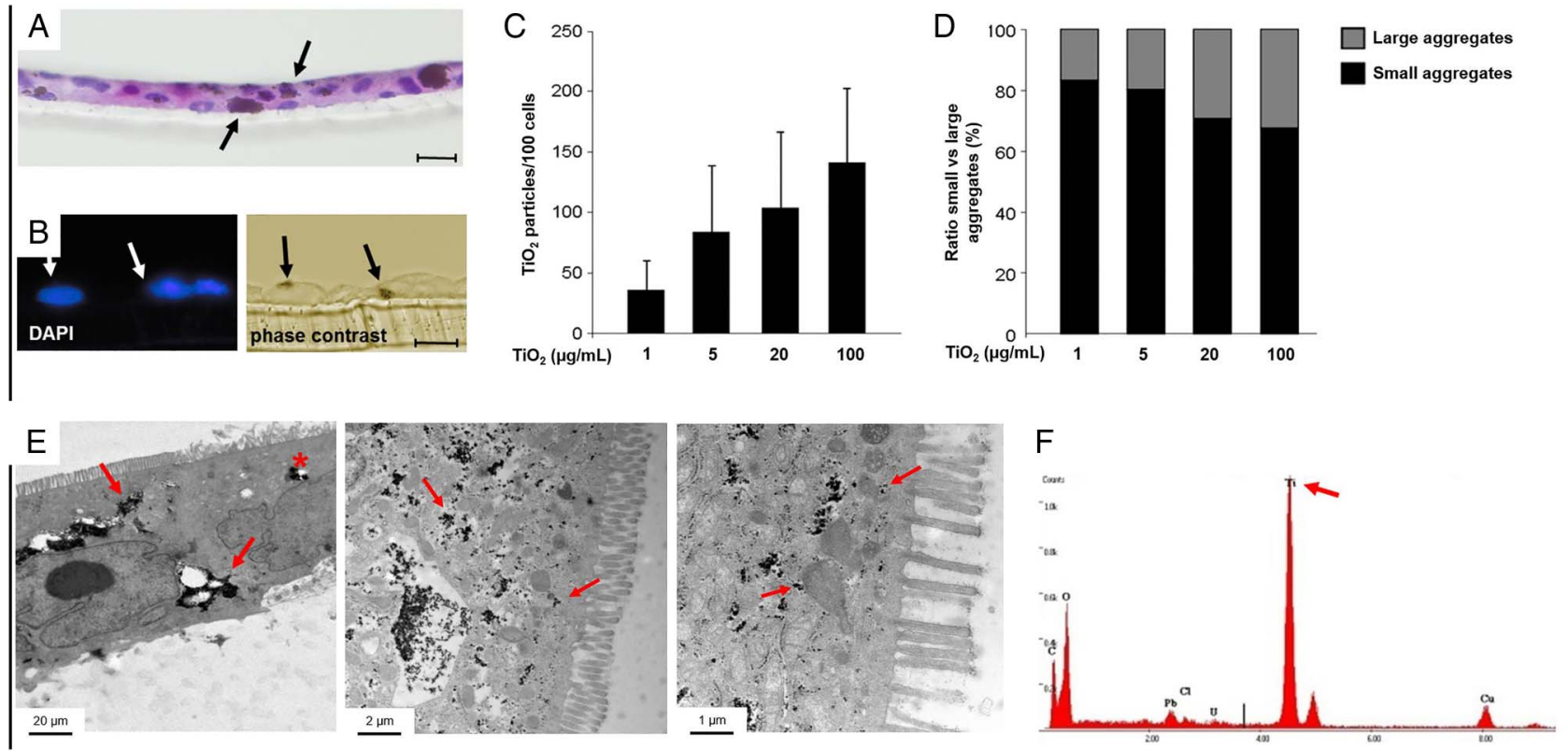

Figure 4 Aggregates of titanium dioxide $\left(\mathrm{TiO}_{2}\right)$ accumulate intracellularly in Caco-2 cells in a dose-dependent manner. (A and $\left.\mathrm{B}\right)$, Caco-2 cells grown on transwells were incubated with $100 \mu \mathrm{g} / \mathrm{mL} \mathrm{TiO}_{2}$ for $24 \mathrm{~h}$. Cross-sections were stained with H\&E (A) or DAPI to visualise nuclei and the same frame was observed in phase-contrast view to identify $\mathrm{TiO}_{2}$ aggregates (B). Scale bar: $25 \mu \mathrm{m}$. $\mathrm{TiO}_{2}$ aggregates were located intracellularly in aggregates of various sizes, indicated by arrows. (C-F) Cross-sections were processed as described above, and $\mathrm{TiO}_{2}$ aggregates and nuclei were counted. Incubation of Caco-2 for $24 \mathrm{~h}$ with indicated amounts of $\mathrm{TiO}_{2}$ resulted in a dose-dependent increase of intracellular TiO ${ }_{2}$ (C). The size of $\mathrm{TiO}_{2}$ aggregates also increased in a dose-dependent manner. Electron dense regions with a diameter larger than $3.5 \mu \mathrm{m}$ were considered as large aggregates (D). Cross-sections were subjected to transmission electron microscopy, revealing electron-dense aggregates indicated by arrows (E). The elemental analysis of a selected region (indicated as asterisk in panel E) confirmed that aggregates contained titanium, which appeared as main peak at $4.5 \mathrm{keV}$ (indicated by arrow) (F).

epithelial barrier function in Caco-2 monolayers. Although small, this effect hints to an influence of $\mathrm{TiO}_{2}$ in epithelial permeability, and is in accordance with studies showing that $\mathrm{TiO}_{2}$ nanoparticles induce tight junction remodelling in the intestinal epithelium of mice. ${ }^{51}$ Mimicking human gut exposure to $\mathrm{TiO}_{2}$ particles in vitro meets often with difficulties: as $\mathrm{TiO}_{2}$ particles are in an aqueous suspension, they tend to precipitate forming blankets by the end of the incubation time. This might negatively affect cellular responses on $\mathrm{TiO}_{2}$ stimulation, especially at high concentrations. The detection of significant ROS production in $\mathrm{TiO}_{2}$-stimulated IECs is in line with previous studies showing that uptake of particulate matter is accompanied by ROS production and inflammasome activation. ${ }^{29} 55$ Strikingly, ICP-MS analysis revealed increased levels of titanium in the blood of patients with UC having active disease, pointing to that the disturbed barrier function associated with IBD allows for a higher translocation of $\mathrm{TiO}_{2}$ nanoparticles into the systemic blood stream. Absorbed $\mathrm{TiO}_{2}$ might enhance inflammation and barrier permeability, facilitating further $\mathrm{TiO}_{2}$ penetration on subsequent exposures. This would support the suggested therapeutic benefit from low inorganic particle diet observed in patients with IBD. For example, the reduction of nano and microparticles in the diet of patients with CD significantly decreased their disease activity within a month of treatment. ${ }^{56}$ In contrast, a posterior multi-centered follow-up with 83 patients with CD did not show any effect of a microparticle free diet. ${ }^{57}$ However, in this trial dietary calcium was also restricted, and effects may have been masked by the corticosteroid treatment received by the participants of the study.

In summary, these findings show that orally administered $\mathrm{TiO}_{2}$ nanoparticles worsen intestinal inflammation in mice through the activation of NLRP3 inflammasome. $\mathrm{TiO}_{2}$ is one of
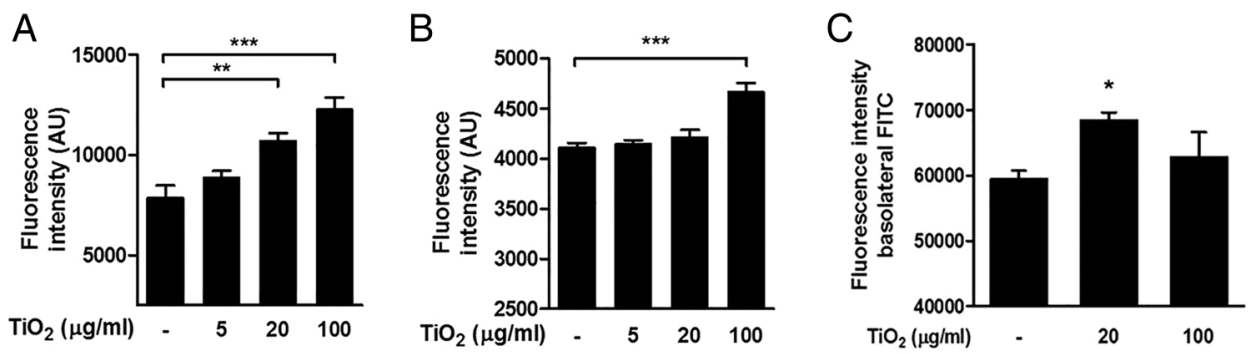

Figure 5 Titanium dioxide $\left(\mathrm{TiO}_{2}\right)$ triggers production of reactive oxygen species (ROS) and influences epithelial permeability in human intestinal epithelial cells (IECS). (A and B) HT-29 showed significantly increased production of ROS at the highest dose of $100 \mu \mathrm{g} / \mathrm{mL}$ of TiO 2 (A). In Caco-2 cells, a significant increase of ROS was detected at $\mathrm{TiO}_{2}$ concentrations of 20 and $100 \mu \mathrm{g} / \mathrm{mL}$ (B). (C) Monolayers of Caco-2 cells were treated with indicated amounts of $\mathrm{TiO}_{2}$ for $24 \mathrm{~h}$, and incubated apically with FITC-labelled beads for $1 \mathrm{~h}$. An increase of basolateral fluorescence was observed in $\mathrm{TiO}_{2}$-treated cells as compared with non-treated cells $\left(n=5,{ }^{* *} p<0.05\right)$. 

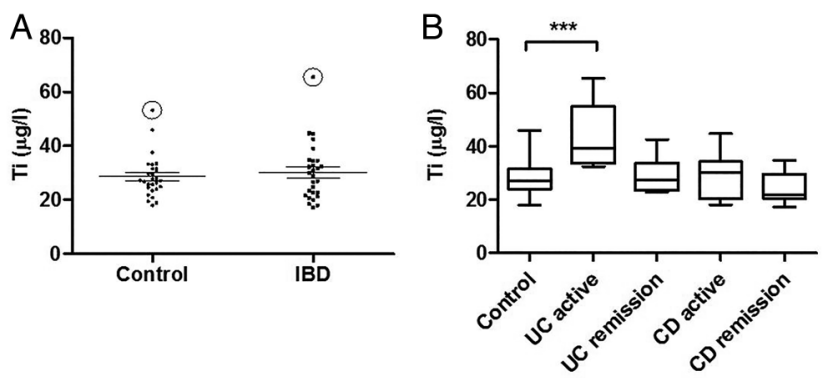

Figure 6 Patients with IBD present elevated titanium levels in blood. ( $A$ and $B$ ) Titanium levels in blood of healthy donors and patients with IBD are shown as measured by inductively coupled plasma mass spectrometry (ICP-MS) (A) ( $n=28$ control, $n=28$ IBD, ${ }^{\circ}$ depicts outliers). Titanium levels in subgroups of patients with IBD; significantly increased levels were detected in samples from patients with active UC (B) ( $n=28$ control, $n=5$ UC active, $n=6$ UC remission, $n=8$ Crohn's disease (CD) active, $n=9$ CD remission; $\left.{ }^{* * *} p<0.001\right)$.

the most produced nanomaterials in the world and its use as food additive is on the rise. Since $\mathrm{TiO}_{2}$ is also used in pharmaceutical formulations, local luminal concentrations of $\mathrm{TiO}_{2}$ might reach substantial levels. Depending on the properties of the pills, they disintegrate at different sections of the GI tract and can affect the epithelium in a very distinct and concentrated manner. A local accumulation of $\mathrm{TiO}_{2}$ may have profound effects on patients with a disturbed barrier function as found in IBD. Very high concentrations of particles are often chosen in toxicity studies to ensure bioactivity across the assays evaluated. Hence, there is a pressing need for biologically relevant human exposure information to facilitate interpretation of assay results. Since the long-term effects of dietary $\mathrm{TiO}_{2}$ may be revealed only in decades, after a lifetime exposition to $\mathrm{TiO}_{2}$, our data suggest a more cautious use of these particles.

Correction notice This article has been corrected since it published online first. An Open Access licence has been added.

Acknowledgements The authors acknowledge the expert technical support from Gery Barmettler in preparing samples for electron microscopy of the Center for Microscopy and Image Analysis, University of Zurich.

Contributors PAR, HMB: Data acquisition, manuscript preparation; BM, SL, KA, MRS, AF-T: Data acquisition; MS, KAW, IF-W, MH, TK: Critical revision; GR: Study supervision and manuscript preparation.

Funding This research was supported by a grant from the Swiss Philanthropy Foundation to GR and research grants from the Swiss National Science Foundation to GR (Grant No. 324730_138291 and 314730_153380) and the Swiss IBD Cohort (Grant No. 314730_153380).

Competing interests None declared.

Provenance and peer review Not commissioned; externally peer reviewed.

Open Access This is an Open Access article distributed in accordance with the Creative Commons Attribution Non Commercial (CC BY-NC 4.0) license, which permits others to distribute, remix, adapt, build upon this work non-commercially, and license their derivative works on different terms, provided the original work is properly cited and the use is non-commercial. See: http://creativecommons.org/ licenses/by-nc/4.0/

\section{REFERENCES}

1 Maloy KJ, Powrie F. Intestinal homeostasis and its breakdown in inflammatory bowel disease. Nature 2011:474:298-306.

2 Scharl M, Rogler G. Inflammatory bowel disease pathogenesis: what is new? Curr Opin Gastroenterol 2012;28:301-9.

3 Rogler G. Interaction between susceptibility and environment: examples from the digestive tract. Dig Dis 2011;29:136-43.

4 Rogler G, Vavricka S. Exposome in IBD: recent insights in environmental factors that influence the onset and course of IBD. Inflamm Bowel Dis 2015;21:400-8.
5 Hanauer SB. Inflammatory bowel disease: epidemiology, pathogenesis, and therapeutic opportunities. Inflamm Bowel Dis 2006:12(Suppl 1):S3-9.

6 Loftus EV Jr. Clinical epidemiology of inflammatory bowel disease: Incidence, prevalence, and environmental influences. Gastroenterology 2004;126:1504-17.

7 Weir A, Westerhoff $P$, Fabricius $L$, et al. Titanium dioxide nanoparticles in food and personal care products. Environ Sci Technol 2012;46:2242-50.

8 EFSA. Opinion of the Scientific Panel on Food Additives, Flavourings, Processing Aids and materials in Contact with Food on a request from the Commission related to the safety in use of rutile titanium dioxide as an alternative to the presently permitted anatase form. EFSA J 2004;163:1-12.

9 Lomer MC, Hutchinson C, Volkert $S$, et al. Dietary sources of inorganic microparticles and their intake in healthy subjects and patients with Crohn's disease. Br J Nutr 2004:92:947-55.

10 [No authors listed]. Specifications for the identity and purity of food additives and their toxicological evaluation: some food colours, emulsifiers, stabilizers, anticaking agents, and certain other substances. Thirtenth report of the Joint FAO-WHO Expert Committee on Food Additives. Rome, 27 May-4 June 1969. World Health Organ Tech Rep Ser 1970;445:1-36.

11 European Parliament C. European Parliament and Council Directive 94/36/EC of 30 June 1994 on colours for use in foodstuffs Official Journal L 237 1994:13-29.

12 Wang J, Li N, Zheng L, et al. P38-Nrf-2 signaling pathway of oxidative stress in mice caused by nanoparticulate $\mathrm{TiO}_{2}$. Biol Trace Elem Res 2011;140:186-97.

13 Bermudez E, Mangum JB, Wong BA, et al. Pulmonary responses of mice, rats, and hamsters to subchronic inhalation of ultrafine titanium dioxide particles. Toxicol Sci 2004;77:347-57.

14 Trouiller B, Reliene $\mathrm{R}$, Westbrook $\mathrm{A}$, et al. Titanium dioxide nanoparticles induce DNA damage and genetic instability in vivo in mice. Cancer Res 2009;69:8784-9.

15 Wang JJ, Sanderson BJ, Wang H. Cyto- and genotoxicity of ultrafine TiO2 particles in cultured human lymphoblastoid cells. Mutat Res 2007;628:99-106.

16 Sohaebuddin SK, Thevenot PT, Baker D, et al. Nanomaterial cytotoxicity is composition, size, and cell type dependent. Part Fibre Toxicol 2010;7:22.

17 Baan R, Straif $K$, Grosse $Y$, et al. Carcinogenicity of carbon black, titanium dioxide, and talc. Lancet Oncol 2006:7:295-6.

18 Wang J, Zhou G, Chen C, et al. Acute toxicity and biodistribution of different sized titanium dioxide particles in mice after oral administration. Toxicol Lett 2007;168:176-85.

19 Borm PJ, Robbins D, Haubold S, et al. The potential risks of nanomaterials: a review carried out for ECETOC. Part Fibre Toxicol 2006;3:11.

20 Powell JJ, Ainley CC, Harvey RS, et al. Characterisation of inorganic microparticles in pigment cells of human gut associated lymphoid tissue. Gut 1996;38:390-5.

21 Lomer MC, Thompson RP, Powell JJ. Fine and ultrafine particles of the diet: influence on the mucosal immune response and association with Crohn's disease. Proc Nutr Soc 2002;61:123-30.

22 Franchi $L$, Eigenbrod T, Muñoz-Planillo $R$, et al. The inflammasome: a caspase-1-activation platform that regulates immune responses and disease pathogenesis. Nat Immunol 2009;10:241-7.

23 Yazdi AS, Guarda G, Riteau N, et al. Nanoparticles activate the NLR pyrin domain containing 3 (Nlrp3) inflammasome and cause pulmonary inflammation through release of IL-1 $\alpha$ and IL-1 $\beta$. Proc Natl Acad Sci USA 2010;107:19449-54.

24 Villani $A C$, Lemire $M$, Fortin $G$, et al. Common variants in the NLRP3 region contribute to Crohn's disease susceptibility. Nat Genet 2009;41:71-6.

25 Mariathasan S, Weiss DS, Newton K, et al. Cryopyrin activates the inflammasome in response to toxins and ATP. Nature 2006:440:228-32

26 Martinon F, Pétrilli V, Mayor A, et al. Gout-associated uric acid crystals activate the NALP3 inflammasome. Nature 2006:440:237-41.

27 Franchi L, Muñoz-Planillo R, Nuñez G. Sensing and reacting to microbes through the inflammasomes. Nat Immunol 2012;13:325-32.

28 Hornung $V$, Bauernfeind $F$, Halle $A$, et al. Silica crystals and aluminum salts activate the NALP3 inflammasome through phagosomal destabilization. Nat Immunol 2008;9:847-56

29 Dostert C, Pétrilli V, Van Bruggen R, et al. Innate immune activation through Nalp3 inflammasome sensing of asbestos and silica. Science 2008;320:674-7.

30 Obermeier F, Kojouharoff G, Hans W, et al. Interferon-gamma (IFN-gamma)- and tumour necrosis factor (TNF)-induced nitric oxide as toxic effector molecule in chronic dextran sulphate sodium (DSS)-induced colitis in mice. Clin Exp Immunol 1999:116:238-45.

31 Becker C, Fantini MC, Neurath MF. High resolution colonoscopy in live mice. Nat Protoc 2006:1:2900-4

32 Hausmann $\mathrm{M}$, Obermeier $\mathrm{F}$, Paper $\mathrm{DH}$, et al. In vivo treatment with the herbal phenylethanoid acteoside ameliorates intestinal inflammation in dextran sulphate sodium-induced colitis. Clin Exp Immunol 2007;148:373-81.

33 Wirtz S, Neufert C, Weigmann B, et al. Chemically induced mouse models of intestinal inflammation. Nat Protoc 2007:2:541-6.

34 Jaggi GP, Harlev M, Ziegler U, et al. Cerebrospinal fluid segregation optic neuropathy: an experimental model and a hypothesis. $\mathrm{Br} J$ Ophthalmol 2010;94:1088-93.

35 Obermeier F, Hausmann M, Kellermeier $\mathrm{S}$, et al. IL-15 protects intestinal epithelia cells. Eur J Immunol 2006;36:2691-9. 
36 Pittet $V$, Juillerat $P$, Mottet $C$, et al. Cohort profile: the Swiss Inflammatory Bowel Disease Cohort Study (SIBDCS). Int J Epidemiol 2009;38:922-31.

37 Harvey RF, Bradshaw JM. A simple index of Crohn's-disease activity. Lancet 1980;1:514.

38 Rachmilewitz D. Coated mesazaline (5-aminosalicylic acid) versus sulphasalazine in the treatment of active ulcerative colitis: a randomised trial. $\mathrm{Br} \mathrm{Med} J$ 1989;298:82-6.

39 Shinohara N, Danno N, Ichinose T, et al. Tissue distribution and clearance of intravenously administered titanium dioxide (TiO(2)) nanoparticles. Nanotoxicology 2014:8:132-41.

40 Chen J, Dong $X$, Zhao J, et al. In vivo acute toxicity of titanium dioxide nanoparticles to mice after intraperitioneal injection. J App/ Toxicol 2009;29:330-7.

41 Tschopp J, Schroder K. NLRP3 inflammasome activation: The convergence of multiple signalling pathways on ROS production? Nat Rev Immunol 2010;10:210-15.

42 Duan Y, Liu J, Ma L, et al. Toxicological characteristics of nanoparticulate anatase titanium dioxide in mice. Biomaterials 2010;31:894-9.

43 Jovanović B. Critical review of public health regulations of titanium dioxide, a human food additive. Integr Environ Assess Manag 2015;11:10-20.

44 Nogueira CM, de Azevedo WM, Dagli ML, et al. Titanium dioxide induced inflammation in the small intestine. World J Gastroenterol 2012;18:4729-35.

45 Bauer C, Duewell P, Mayer C, et al. Colitis induced in mice with dextran sulfate sodium (DSS) is mediated by the NLRP3 inflammasome. Gut 2010;59:1192-9.

46 Zaki MH, Boyd KL, Vogel P, et al. The NLRP3 inflammasome protects against loss of epithelial integrity and mortality during experimental colitis. Immunity 2010;32:379-91

47 Hirota SA, Ng J, Lueng A, et al. NLRP3 inflammasome plays a key role in the regulation of intestinal homeostasis. Inflamm Bowel Dis 2011;17:1359-72.
48 Song-Zhao GX, Srinivasan N, Pott J, et al. Nlrp3 activation in the intestinal epithelium protects against a mucosal pathogen. Mucosal Immunol 2014;7:763-74.

49 Walczak AP, Fokkink R, Peters $\mathrm{R}$, et al. Behaviour of silver nanoparticles and silver ions in an in vitro human gastrointestinal digestion model. Nanotoxicology 2013; 7:1198-210.

50 Peters $\mathrm{R}$, Kramer $\mathrm{E}$, Oomen AG, et al. Presence of nano-sized silica during in vitro digestion of foods containing silica as a food additive. ACS Nano 2012;6: 2441-51.

51 Brun E, Barreau F, Veronesi G, et al. Titanium dioxide nanoparticle impact and translocation through ex vivo, in vivo and in vitro gut epithelia. Part Fibre Toxicol 2014;11:13.

52 Sang $X$, Fei $M$, Sheng $L$, et al. Immunomodulatory effects in the spleen-injured mice following exposure to titanium dioxide nanoparticles. J Biomed Mater Res $A$ 2014; 102:3562-72.

53 Geiser M, Rothen-Rutishauser B, Kapp N, et al. Ultrafine particles cross cellular membranes by nonphagocytic mechanisms in lungs and in cultured cells. Environ Health Perspect 2005;113:1555-60.

$54 \mathrm{Mu}$ Q, Hondow NS, Krzemiński L, et al. Mechanism of cellular uptake of genotoxic silica nanoparticles. Part Fibre Toxicol 2012;9:29.

55 Schanen BC, Das S, Reilly CM, et al. Immunomodulation and Thelper TH1/TH2 response polarization by $\mathrm{CeO}_{2}$ and $\mathrm{TiO}_{2}$ nanoparticles. PLOS ONE 2013;8:e62816.

56 Lomer MC, Harvey RS, Evans SM, et al. Efficacy and tolerability of a low microparticle diet in a double blind, randomized, pilot study in Crohn's disease. Eur J Gastroenterol Hepatol 2001;13:101-6.

57 Lomer MC, Grainger SL, Ede R, et al. Lack of efficacy of a reduced microparticle diet in a multi-centred trial of patients with active Crohn's disease. Eur J Gastroenterol Hepatol 2005; 17:377-84. 